\title{
BIOTHERMAL CONTRASTS WHILE TRAVELLING IN OR BETWEEN POLAND AND BULGARIA
}

\author{
Pawel Milewski, Jakub Szmyd \\ Institute of Geography and Spatial Organization \\ Polish Academy of Sciences \\ Twarda 51/55, 00-818 Warsaw, Poland \\ pmilewski@twarda.pan.pl,j.szmyd@twarda.pan.pl
}

\begin{abstract}
Given that the number of tourists travelling between Poland and Bulgaria increases every year, this article considers the adaptation strain facing those who move between certain sites on national or international routes. The Adaptation Strain Index (ASI) was applied for this purpose, and seasonal and spatial patterns of bioclimatic contrasts were considered. While travel within one or other of the countries does not prove particularly oppressive, it may sometimes lead to moderate adaptation strain. In contrast, international travel may prove especially stressful in summer and winter, to the extent that even very strong adaptation strain may be evoked. The results confirm the utility of the Adaptation Strain Index in measuring the bioclimatic contrasts between different locations.
\end{abstract}

Keywords: Adaptation Strain Index, ASI, bioclimate, Bulgaria, Poland, tourism.

\section{Introduction}

Across the world, tourist activity is increasing, with the number of international arrivals in fact rising from 436 million in 1990 to 1133 million in 2014 (Eurostat 2015, UNWTO 2015). Tourist activity between Poland and Bulgaria has likewise been enhanced, both because and in spite of the fact that Bulgaria has long been a favoured holiday destination among Poles. In 2014, the number of Polish residents visiting Bulgaria reached 162,200, with the main purposes of the trip for no fewer than 153,600 of these being holidays, leisure and recreation. In the same year, the number of Bulgarian tourists in Poland reached 121,100, with this being 149\% of the level noted in 2009 (Fig. 1) (CSO 2010, 2011, 2012, 2013, 2014, 2015). 


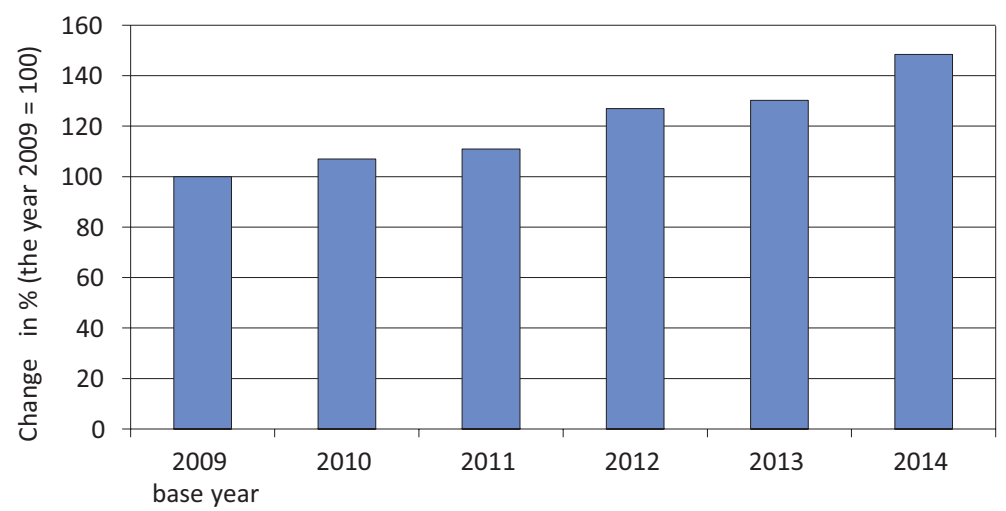

Figure 1. Percentage change in the number of Bulgarian tourists visiting Poland in the 2009-2014 period (authors' own elaboration)

The climates of Poland and Bulgaria differ (Kuchcik 2015, this issue), in that, according to the Köppen-Geiger classification, the former lies within the humid continental climate zone (Peel et al. 2007), while the latter is much more diversified, and even includes zones of humid subtropical climate in the coastal regions and in the south, as well as an oceanic climate in the east, a humid continental climate in the centre and in the north, and subarctic climates in the highest parts of the mountains. Such a level of differentiation leaves it a matter of cardinal importance that tourists be informed about bioclimate contrasts in Bulgaria, given that their organisms must adapt to new ambient conditions at their (one or more) destinations within the country being visited.

Only a few attempts have been made to find objective methods of assessing bioclimatic contrasts between two sites. The application of two of these relate to the area of Poland or Bulgaria. In 2003, Mateeva and Filipov proposed the Bioclimatic Distance (BD) index, which envisages the thermal insulation of the clothing necessary for heat balance in the organism to be maintained. This was applied in assessing the variation in bioclimate associated with different altitudes and forms of relief in Bulgaria's south-western Rila-Rhodopy region. An evaluation of the spatial variability characterising Poland was in turn carried out by Błażejczyk (2011), using the Bioclimatic Contrast Index (BCI), which comprises four different measures and represents the whole range of thermal environments. Its application likewise confirmed the separate nature of different bioclimatic regions present in Poland. Another index, developed by de Freitas and Grigorieva (2009), is the Acclimatisation Thermal Strain Index (ATSI), which is based around the concept of heat loss by respiration. The authors used ATSI in a bioclimatic assessment of Siberia.

All of the indicators referred to have their strong and weak points, as discussed by Błażejczyk (2011). Taking into consideration the limitations of the indices in question, Błażejczyk and Vinogradova (2014) proposed the new index that has been applied in the research presented here, with a view to assessing the adaptation strain incurred as travel takes place between certain sites in Poland and Bulgaria. 


\section{Material and methods}

In estimating biothermal contrasts during the national and international trips studied, analysis centred on hourly meteorological data for a typical year extracted from the METEONORM 7.0 database in respect of five stations, i.e. Kołobrzeg and Warsaw in Poland, Sofia and Varna in Bulgaria, and Štrbské Pleso in Slovakia. For its calculation of values for a typical meteorological year, the METEONORM database refers to real observations regarding solar radiation in the 1985-2005 period, or else 2000-2009, in the case of air temperature, air humidity and wind velocity.

The weather stations selected are deemed representative of places of frequent tourist activity (Fig. 2). While Warsaw (106 m a.s.1.) and Sofia (586 m a.s.1.) illustrate conditions in the two countries' capital cities, Kołobrzeg (5 m a.s.1.) and Varna (41 $\mathrm{m}$ a.s.1.) represent the respective coastal regions, i.e. those of the Baltic and Black Seas. In addition, a station in a mountainous area was selected, with Štrbské Pleso (1356 m a.s.1.) illustrating conditions in the Tatra Mountains. This station was treated as located in Poland. The study goes on to consider travel between these points on the routes presented in Figure 2.

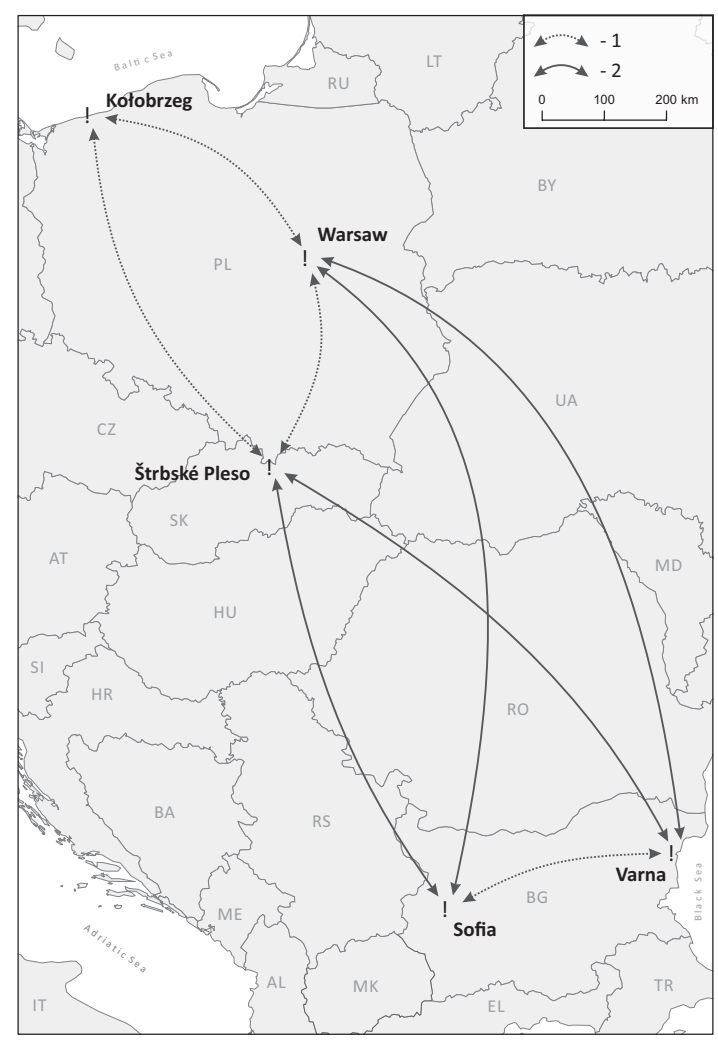

Figure 2. Meteorological stations and routes of travel between them considered in the research described here (1 - domestic trips, 2 - international trips)

The evaluation of the biothermal contrasts experienced by tourists entailed application of the Adaptation Strain Index (ASI, no dimension), which was developed by Błażejczyk and Vinogradova 
(2014) as a modification of the Bioclimatic Contrast Index (Błażejczyk 2011). The index illustrates the adaptation strain tourists can be subject to as they reach a chosen destination. It includes three measures of processes by which a person's organism adapts to different ambient conditions, i.e. the water loss index $\left(\mathrm{SW}, \mathrm{g} \cdot\right.$ hour $\left.^{-1}\right)$, the Insulation Predicted index (Iclp, clo) and the Universal Thermal Climate Index (UTCI, ${ }^{\circ} \mathrm{C}$ ). The water loss index is an indicator of adaptation to hot conditions through perspiration and the evaporation of sweat from the skin (Błażejczyk 2007). The Insulation Predicted index is a measure of adaptation to cold through changes in the insulative properties of clothing (Burton \& Edholm 1955, Fourt \& Hollies 1970, Havenith et al. 2012). The Universal Thermal Climate Index in turn points to the physiological response of an organism to actual ambient conditions (Bröde et al. 2012, Błażejczyk et al. 2013).

Values of the resultant Adaptation Strain Index are categorised in relation to 11 classes (Tab. 1). Negative values for the ASI indicate 'cooler' conditions at the chosen destination than at the initial location. Likewise, positive values illustrate 'warmer' conditions.

Table 1. Categories of Adaptation Strain Index (ASI) (Błażejczyk \& Vinogradova, 2014; modified)

\begin{tabular}{|c|c|c|}
\hline ASI category & ASI range & ASI description \\
\hline 5 & $>27.40$ & Extreme adaptation strain due to heat \\
\hline 4 & from 20.56 to 27.40 & Very strong adaptation strain due to heat \\
\hline 3 & from 13.66 to 20.55 & Strong adaptation strain due to heat \\
\hline 2 & from 6.81 to 13.65 & Slight adaptation strain due to heat \\
\hline 1 & from 0.01 to 6.80 & No adaptation strain \\
\hline 0 & 0 & Slight adaptation strain due to cold \\
\hline-1 & from -0.01 to -6.50 & Moderate adaptation strain due to cold \\
\hline-2 & from -6.51 to -13.05 & Strong adaptation strain due to cold \\
\hline-3 & from -13.06 to -20.55 & Very strong adaptation strain due to cold \\
\hline-4 & from -20.56 to -29.10 & Extreme adaptation strain due to cold \\
\hline-5 & $<-29.10$ &
\end{tabular}

All the components of the Adaptation Strain Index were calculated using the BioKlima 2.6 software packagel. The calculations of ASI were made for 12 midday local time at a pair of locations, with account taken of changes to summer or winter time. Midday meteorological observations were considered to represent the time of most intensive human activity. Changes in the physiological parameters of the human organism in the course of the actual travel between locations were not taken into account in this paper, which is to say that movement between the initial and target locations was treated as instantaneous. Mean ASI values and frequencies of occurrence of different ASI categories were used in characterising the seasons.

\footnotetext{
1 http://www.igipz.pan.pl/Bioklima-zgik.html
} 


\section{Results}

\section{Travel in Poland}

Table 2 (part 'A') characterises ASI as calculated for pairs of studied localities in Poland. On average, the adaptation strain evoked by travel in Poland is not large. The highest value of ASI (0.57) is that characterising travel transfer from Warsaw to the Tatra Mountains, while the lowest $(-0.63)$ relates to the trip in the opposite direction. Positive average values for ASI characterise transfers from Warsaw to the Baltic coast, from Warsaw to the Tatras, and from the sea to the mountains. All of these trips therefore entail adaptation to heat, or warmer conditions. In each case, travel in the opposite direction requires adaptation to cold, or cooler conditions.

The maximum reported ASI value (10.60) is that associated with the transfer between the Baltic coast and Warsaw. It indicates moderate adaptation strain in response to heat. The lowest maximum value for ASI is in turn the 6.24 characterising travel in the reverse direction and indicative of 'slight' adaptation strain induced by heat. Maximum positive values for the index mostly arise in summer. Only in the case of a transfer between the Baltic and Warsaw does a maximum value appear in the autumn.

The lowest minimum value for ASI was in turn found for the transfer between the Tatras and Warsaw (-8.94, denoting moderate adaptation strain related to cold). The highest minimum value $(-5.04)$ is in turn observed for travel from Warsaw to the Baltic Sea, and it indicates slight adaptation strain relating to cold. Minimum values for ASI occur in different seasons, depending on the travel direction.

The largest range of ASI variation is typical for trips to Warsaw. The value is 19.50 in the case of travel from the Tatras and 17.32 where the transfer is from the Baltic coast. In these cases, adaptation strain extends from 'moderate adaptation strain due to cold' to 'moderate adaptation strain due to heat'. The lowest amplitude value was that found for a trip from Warsaw to the Baltic Sea (11.29).

As travel is planned, consideration must also be given to the frequency of occurrence of conditions different from those at the home location. Figure 3 presents the frequency of occurrence of the ASI categories. In general, travel in Poland is seen to be associated with possible adaptation strain ranging between slight adaptation to either cold or heat. On average, the frequency of occurrence of the '-1', ' 0 ' or ' 1 ' categories during a year is similar (at 20-40\%). The frequency of occurrence of categories obviously fluctuates from season to season, with spring and summer trips from the Baltic and the Tatras to Warsaw for example necessitating moderate adaptation to heat. Such situations are also observed in the cases of summer or winter transfers between Warsaw and the mountains, as well as summer travel from the Baltic coast to the mountains. However, issues arise less frequently (only on up to $2 \%$ of the days in a year). Travel from the Tatras or the Baltic to Warsaw, as well as between the seaside and the mountains, may entail moderate adaptation strain due to cold (on up to $3 \%$ of the days in a year). However, during all winter trips the frequency of occurrence of the ' 0 ' category - denoting no adaptation strain at all - is very low (at $1 \%$ ), if indeed this category is present at all. 
Table 2. Average, maximum and minimum values of ASI, as well as the amplitude to ASI values between the studied locations for the different seasons and the year (A - domestic trips in Poland, B - domestic trips in Bulgaria, C - international trips)

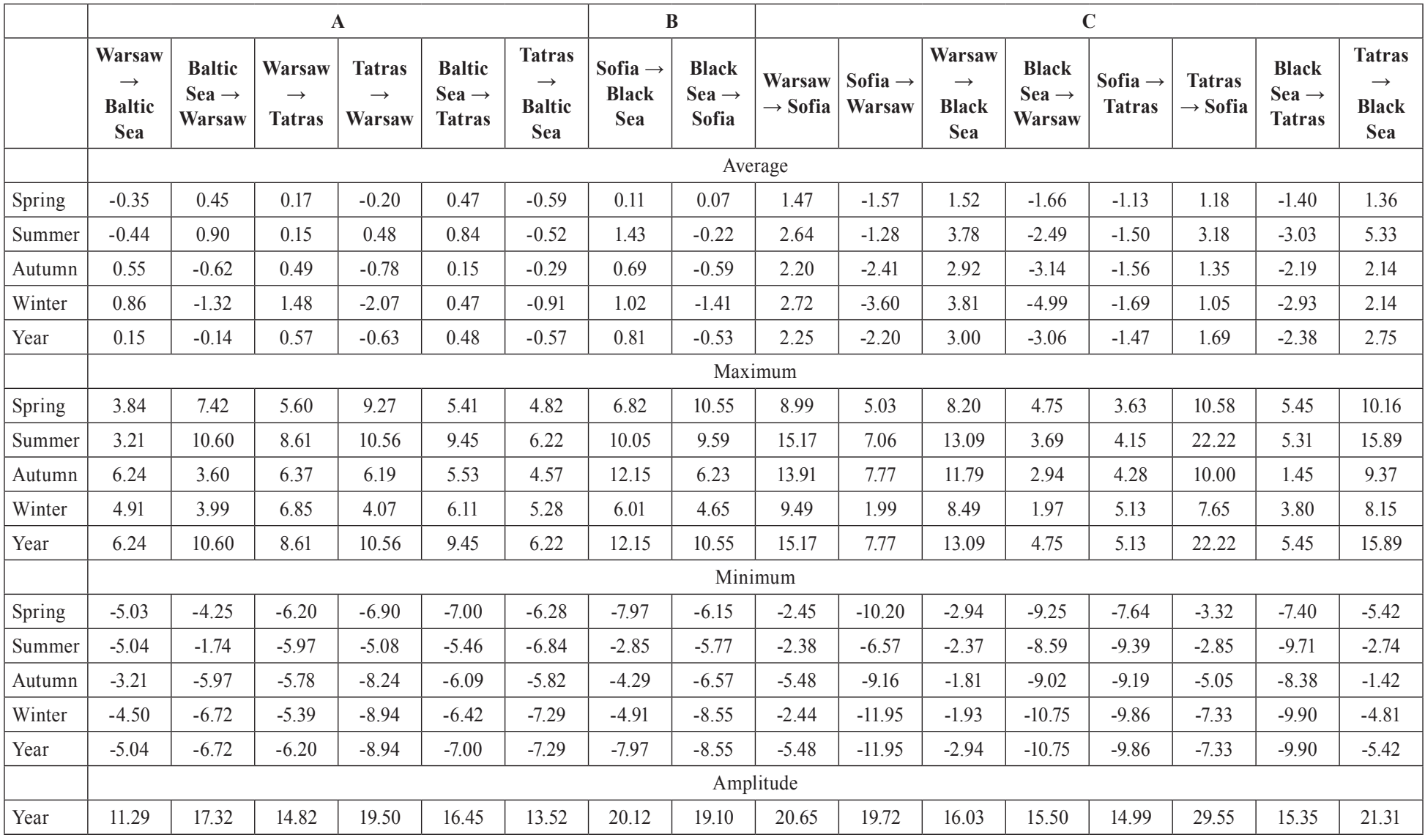



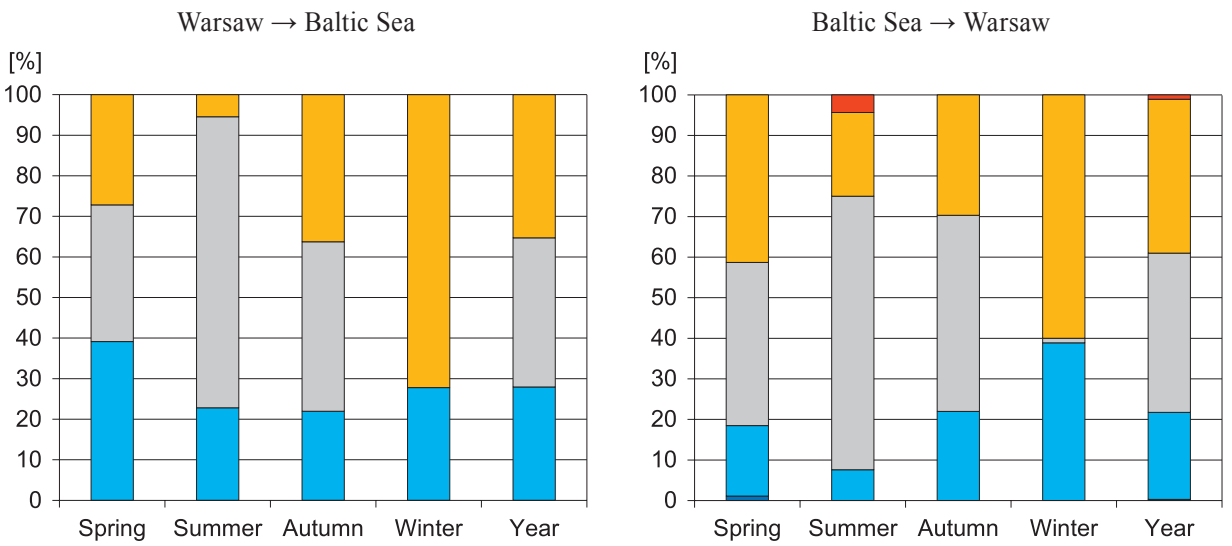

Warsaw $\rightarrow$ Tatras

[\%]

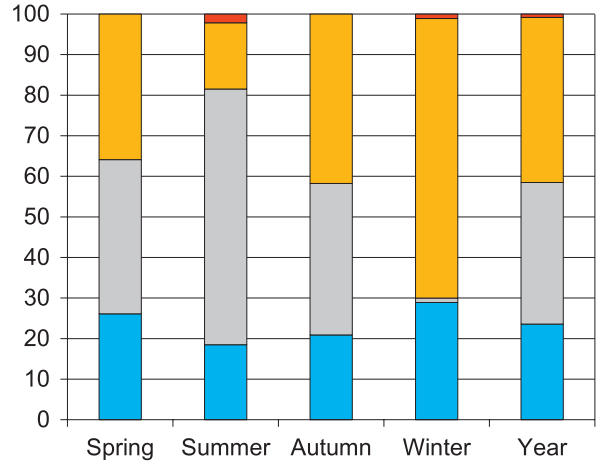

Tatras $\rightarrow$ Warsaw

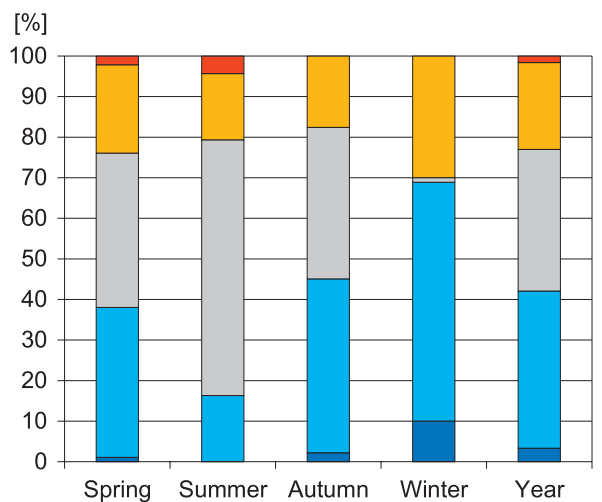

Baltic Sea $\rightarrow$ Tatras

[\%]

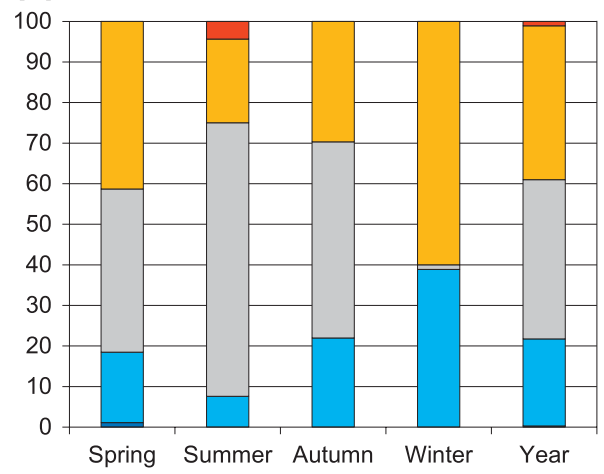

[\%]

Tatras $\rightarrow$ Baltic Sea

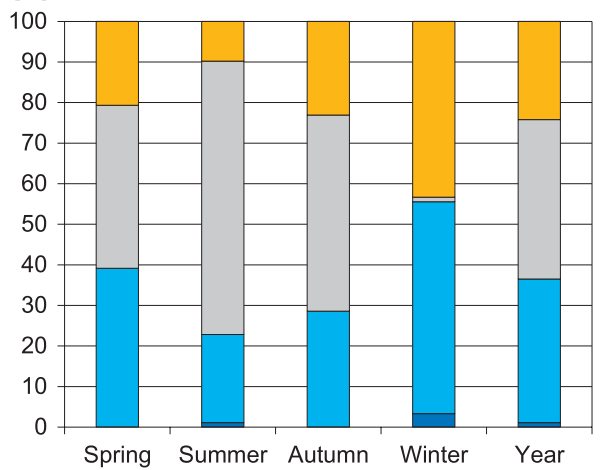

very strong adaptation strain due to heat

strong adaptation strain due to heat

moderate adaptation strain due to heat

slight adaptation strain due to heat no adaptation strain slight adaptation strain due to cold

moderate adaptation strain due to cold

Figure 3. Frequency of occurrence of the different ASI categories in the case of trips taken in Poland 


\section{Travel in Bulgaria}

In the case of Bulgaria, there is only one pair of points for which transfers are analysed. Part ' $\mathrm{B}$ ' of Table 2 characterises these, and it is to be noted that - as domestically in Poland, the adaptation strain when making transfers within Bulgaria is not great. Where averaged values are concerned, a transfer from Sofia to the Black Sea coast entails a need for slight adaptation to heat $(\mathrm{ASI}=0.81)$. Travel in the opposite direction requires slight adaptation to cooler conditions (ASI $=-0.53$ ). Equally, travel from Bulgaria's capital to its sea coast requires adaptation to heat in all seasons, while such adaptation is only necessitated where travel from the seaside to the capital takes place in spring. Other seasons require adaptation to cold in the case of this direction of transfer.

The maximum value for ASI was found in the case of travel from Sofia to the Black Sea (12.15). This value indicates moderate adaptation strain due to heat, and arises in autumn. The lowest minimum value for ASI in turn describes the trip from the seaside area to the capital (-8.55). In such conditions, during winter, moderate adaptation strain to cold is necessary. The range of ASI values is 20.12 for the trip from Sofia to the Black Sea and 19.10 for the transfer in the reverse direction.

Transfers between Sofia and the Black Sea are characterised by a prevalent need to adapt to heat. This is true of more than $40 \%$ of days in a given year, with seasonal variation between $28 \%$ of autumn days and $66 \%$ of those in winter. Analogously, travel from the seaside area to the capital sees a dominance of days on which adaptation to cold is necessitated. The spring trips to the seaside may prove the most diversified, given that adaptation strain may range through 5 categories of ASI, starting from 'moderate adaptation strain to cold' and ending on 'moderate adaptation strain to heat'. Days giving rise to moderate adaptation strain to heat also occur on this route in summer and autumn. People may also experience it when travelling in the reverse direction in spring and summer. Autumn and winter travel from the Black Sea to Sofia may lead to moderate adaptation strain induced by cold. Equally, situations with a lack of adaptation strain characterise more than $30 \%$ of the days in a year, although they are the most common in autumn (60\% of days) and relatively rare in winter (7\%).

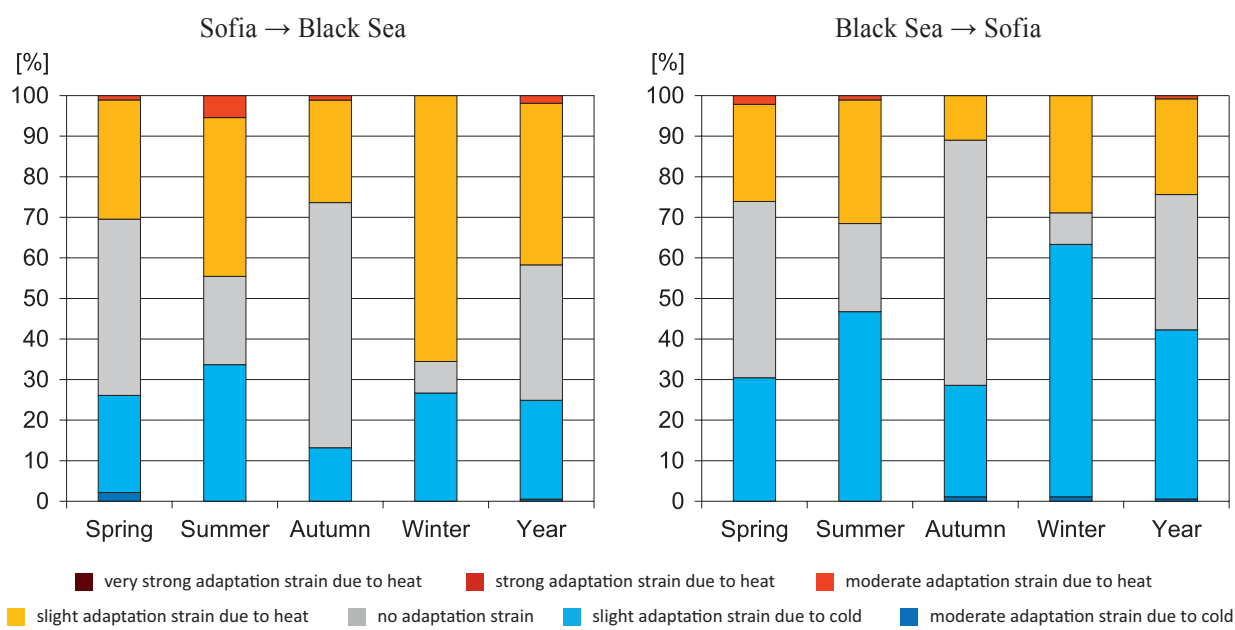

Figure 4. Frequency of occurrence of ASI categories characterising domestic trips within Bulgaria 


\section{International travel}

The Polish-Bulgarian and Bulgarian-Polish international journeys prove to be associated with a much higher diversity of adaptation strains than those taken domestically (Tab. 2, Part ' $\mathrm{C}$ '). The highest mean value for ASI was found for a transfer between Warsaw and the Black Sea (3.00). The lowest mean value (-3.06) is in turn observed for the reverse trip. The average values of ASI are negative for all transfers in the Bulgaria-Poland direction. Consequently, all journeys to Bulgaria are characterised by positive ASI values.

The highest maximum value for ASI was noted for the summer trip from the Tatra Mountains to Sofia (22.22). This indicates a very profound reaction of the human organism to new ambient conditions, in fact pointing to very strong adaptation strain due to heat (category '4'). The four highest maximum values for ASI are observed for summer transfers from Poland to Bulgaria. This is of relevance, given the fact that most trips on this route are actually made in summer. In essence, the finding offers confirmation that summers in Bulgaria are much warmer than those in Poland.

The lowest minimum value of ASI is typical for winter travel from Sofia to Warsaw (-11.95). This value indicates moderate strain due to adaptation to cold. Generally, winters in Poland are cooler than in Sofia or at the Bulgarian seaside, and the four lowest minimum values of ASI were all found for winter transfers from Bulgaria to Poland.

The largest range of ASI variation characterises the trip from the Tatras to Sofia. Its value is 29.55, and this includes categories ranging from 'moderate adaptation strain due to cold' through to 'very strong adaptation strain due to heat'. It is surprising that, for the trip in the opposite direction, the amplitude of ASI values is only 14.99 - a value only around half as high. This is in fact the lowest value for amplitude that was found. More detailed research would be needed to account for this phenomenon.

Travel from Poland to Bulgaria usually requires that people adapt to warmer conditions (Fig. 5). Such situations occur in fact occur on $48-69 \%$ of the days in a year when the travel is from Warsaw or the Tatras. Adaptation is an almost ubiquitous phenomenon in winter - associated with even $95 \%$ of days in the case of travel from Warsaw to the Black Sea. The highest burdens imposed by hot conditions of course occur in summer. At this time of the year the transfer form Warsaw to Sofia and from the Tatras to the Black Sea may evoke strong adaptation strain due to heat (on up to $5 \%$ of days). As was mentioned previously, travels from the Tatras to the capital of Bulgaria can even lead to very strong adaptation strain due to heat, though admittedly only rarely (on $1 \%$ of the days in summer). It is also on this route that the range of possible adaptation strains is seen to be greatest - encompassing 6 categories of ASI. Travel to Poland is usually in turn related to a change to cooler conditions. This adaptation to cold is required in winter especially - only in the case of travel from the Black Sea to the Tatras are greatest burdens imposed in summer. This is connected with particularly marked differences in weather conditions between the mountains of Poland and the coastal area in Bulgaria, where a humid subtropical climate is to be observed. As a result, neutral adaptation conditions ('no adaptation strain' - class ' 0 ') occur in $25-38 \%$ of the days in a year - and usually during $25-50 \%$ of the days from spring through to autumn. Such conditions are observed only very rarely in winter, however; and they are also relatively rare in the case of summer transfers from the Black Sea to the Tatras. 
Transfers to Bulgaria
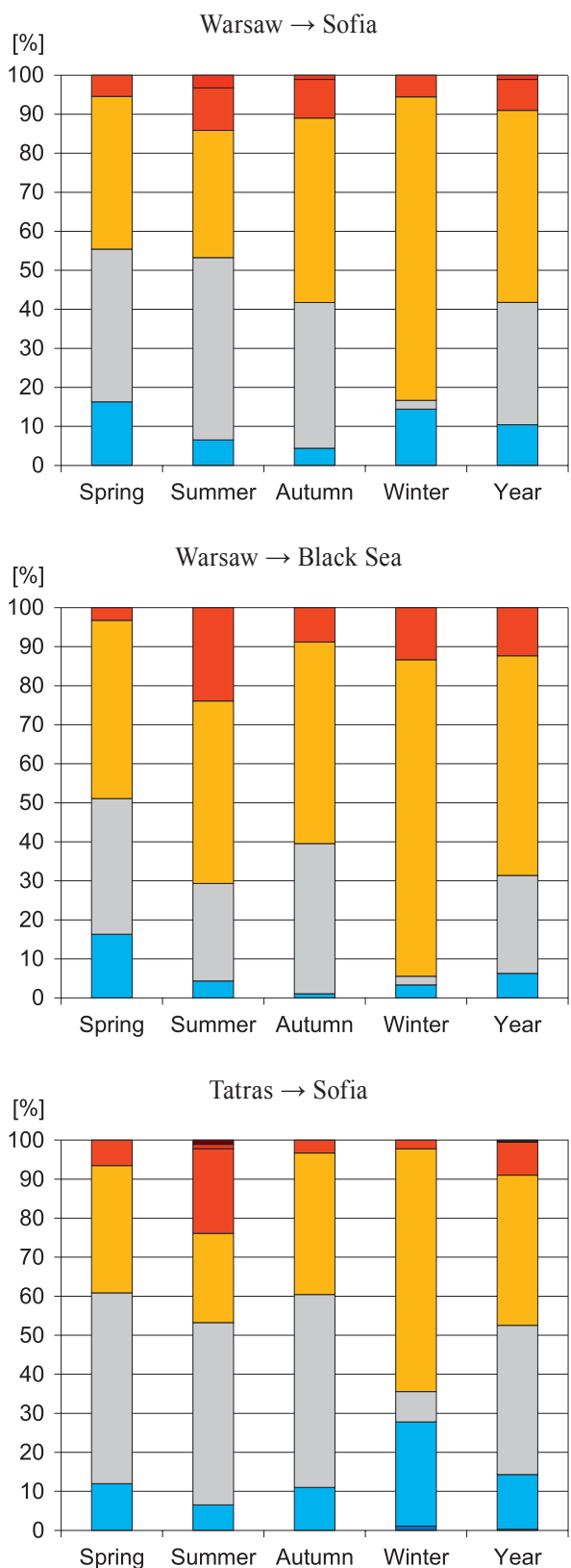

\section{Transfers to Poland}

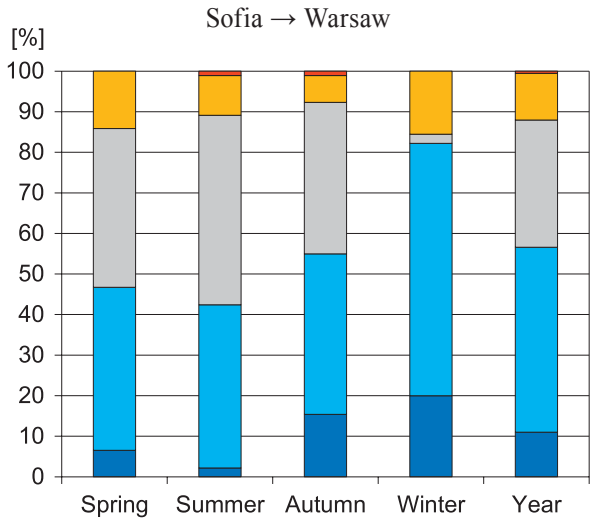

[\%] Black Sea $\rightarrow$ Warsaw
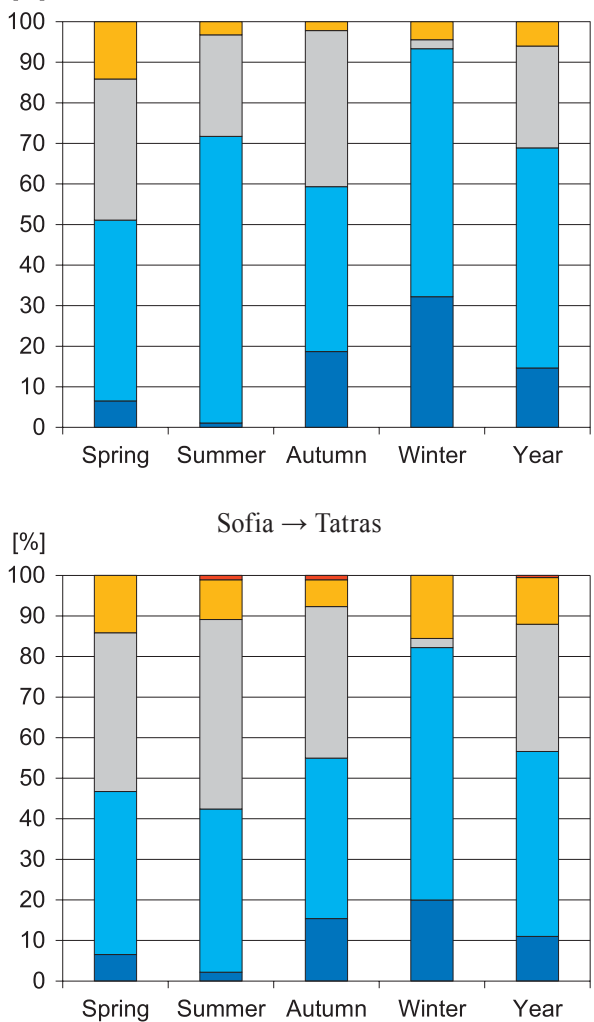


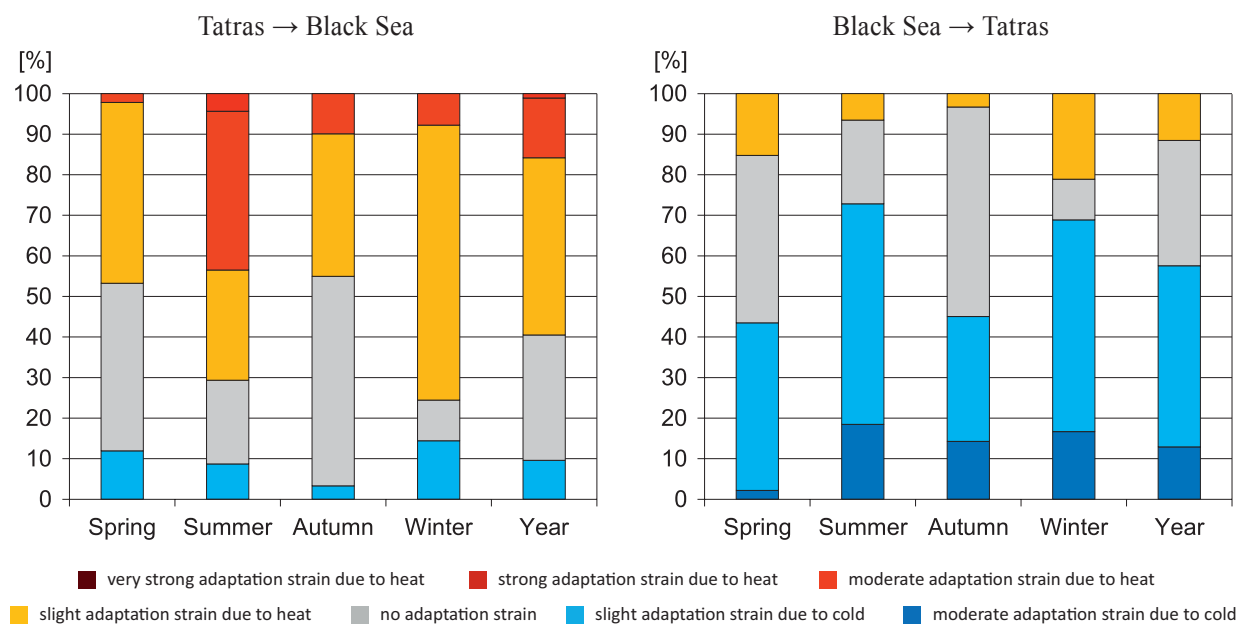

Figure 5. Frequency of occurrence of the different ASI categories in the case of international trips

\section{Conclusions}

While the planning of a tourist trip requires that account be taken of a variety of factors, including price, attractiveness, transport options and weather, it may quite often be the last factor that plays the most important role in the choice of destination and timing for a holiday. Quite typically, the weather at the holiday destination differs markedly from that at the home location, and, while healthy young people can adapt quite easily to such new conditions, abrupt and major changes of ambient conditions can prove very stressful for children, the elderly, and unhealthy people.

The research described in this paper confirms differences between the climates of Poland and Bulgaria - especially in summer and winter. This implies that residents of Poland travelling to Bulgarian destinations in summer need to remember to pack appropriate clothing - mostly lighter than that used at home. Visitors must also remember to drink enough water to assure their protection against dehydration. Nevertheless, thermal conditions may sometimes prove so stressful that it may be better for some to consider travelling at another time of the year. Adequacy of clothing will also need to be borne in mind as a transfer from Bulgaria to Poland is made. In winter in particular, warmer clothing is indicated. While travel within either Bulgaria or Poland is shown to be less oppressive for the human organism, atmospheric conditions in these circumstances also, may at times lead to moderate adaptation strain.

The work described here has made use of a new bioclimatic tool in the form of the Adaptation Strain Index (ASI). Results for it confirm the usefulness of this measure of bioclimatic contrasts between different locations. ASI takes account of both the direction and intensity of adaptation processes in the human organism, while its mathematical formulation allows for the contrasts characterising particular days to be defined. This tool can therefore be of use as patients are being directed to one health resort or another. Use in weather forecasts is also possible. 


\section{References}

Błażejczyk K., 2007. Multiannual and seasonal weather fluctuations and tourism in Poland. [in:] B. Amelung, K. Błażejczyk, A. Matzarakis (eds.), Climate Change and Tourism Assessment and Coping Strategies, pp. 69-90.

Błażejczyk K., 2011. Assessment of regional bioclimatic contrasts in Poland. Miscellanea Geographica, 15, pp. 77-91.

Błażejczyk K., Jendritzky G., Bröde P., Fiala D., Havenith G., Epstein Y., Psikuta A., Kampmann B., 2013. An introduction to the Universal Thermal Climate Index (UTCI). Geographia Polonica, vol. 86 , no. 1 , pp. 5-10.

Błażejczyk K., Vinogradova V., 2014. Adaptation Strain Index for tourists travelling from Central and Northern Europe to the Mediterranean. Finisterra, XLIX, vol. 98, pp. 135-152.

Bröde P., Fiala D., Błażejczyk K., Holmér I., Jendritzky G., Kampmann B., Tinz B., Havenith G., 2012. Deriving the operational procedure for the Universal Thermal Climate Index (UTCI). Int J Biometeorol, vol. 56, no. 3, pp. 481-494.

Burton A.C., Edholm O.G., 1955. Man in a cold environment: physiological and pathological effects of exposure to low temperatures. London: E Arnold Publ, $287 \mathrm{pp}$.

CSO, 2010. Tourism in 2009. Warsaw: Central Statistical Office, 183 pp.

CSO, 2011. Tourism in 2010. Warsaw: Central Statistical Office, 193 pp.

CSO, 2012. Tourism in 2011. Warsaw: Central Statistical Office, 208 pp.

CSO, 2013. Tourism in 2012. Warsaw: Central Statistical Office, 203 pp.

CSO, 2014. Tourism in 2013. Warsaw: Central Statistical Office, 237 pp.

CSO, 2015. Tourism in 2014. Warsaw: Central Statistical Office, 254 pp.

Eurostat, 2015. Tourism statistics at regional level. Eurostat, http://ec.europa.eu/eurostat/statisticsexplained/index.php/Tourism_statistics_at_regional_level [30 November 2015].

Fourt J., Hollies N.R.S., 1970. Clothing. Comfort and function. New York: M Dekker Inc, 254 pp.

de Freitas C.R., Grigorieva E.A., 2009. The Acclimatization Thermal Strain Index (ATSI): a preliminary study of the methodology applied to climatic conditions of the Russian Far East, Int J Biometeorol, vol. 53, no. 4, pp. 307-315.

Havenith G., Fiala D., Błażejczyk K., Richards M., Bröde P., Holmér I., Rintamaki H., Benshabat Y., Jendritzky G., 2012. The UTCI-clothing model. Int J Biometeorol, vol. 56, no. 3, pp. 461-470.

Mateeva Z., Filipov A., 2003. Bioclimatic distance index in the Rila-and-Rhodopy area of Bulgaria. [in:] K. Błażejczyk, B. Krawczyk (eds.), Postępy w badaniach klimatycznych i bioklimatycznych, Prace Geograficzne IGiPZ PAN, vol. 188, pp. 295-302.

Peel M.C., Finlayson B.L., McMahon T.A., 2007. Updated world map of the Köppen-Geiger climate classification. Hydrology and Earth System Sciences, vol. 11, no. 5, pp. 1633-1644.

UNWTO, 2015. UNWTO Tourism Highlights, http://mkt.unwto.org/publication/unwto-tourismhighlights-2015-edition [30 November 2015]. 